Check for updates

The BMJ

Cite this as: $B M J 2020 ; 370: m 3431$ http://dx.doi.org/10.1136/bmj.m3431 Published: 03 September 2020

\section{Suicide rates continue to rise in England and Wales}

\section{Gareth lacobucci}

The Royal College of Psychiatrists has called for more research to understand why numbers of deaths by suicide in certain groups are increasing in England and Wales, after new figures showed a continuing rise last year.

Data published by the Office for National Statistics on 1 September showed that in 2019 the suicide rate among men and boys was 16.9 deaths per 100 ooo, the highest since 2000 and slightly above the 2018 rate of 16.2 per 100 0oo. The suicide rate among women and girls was 5.3 deaths per 100000 in 2019, up from 5.0 per 100000 in 2018 and the highest since 2004.

Overall, 5691 suicides (4303 in men and boys) were registered in England and Wales in 2019, giving an age standardised rate of 11 deaths per 100 ooo people. A total of 5420 were registered in 2018 (10.5 per 100 000).

Among men and boys the age group with the highest suicide rate was 45 to 49 years (25.5 deaths per 100 ooo), while among women and girls 50 to 54 year olds had the highest rate (7.4 per 100 000).

Despite a low number of deaths overall among people aged under 25 years, the data showed that rates of suicide in this age group have generally increased in recent years, particularly in the case of 10 to 24 year old females, whose rate has increased by $94 \%$ since 2012, from 1.6 deaths per 100 ooo (81 deaths) to 3.1 per 100000 in 2019 (159).

Adrian James, president of the Royal College of Psychiatrists, said it was crucial to identify the people most at risk and to provide tailored care and support to them. He said, "This data provides real insight into particular groups in society who are at higher risk. We need more research to understand the reasons behind the increased rates of suicide in teenage girls and young women, as well as middle aged men.

“The current pandemic and its impact on people's mental health reinforces the need for substantial and sustained government funding to ensure that there is a mental health system where no one, including those at risk of suicide, is unable to access the care they need."

The Office for National Statistics said, “Generally, higher rates of suicide among middle aged men in recent years might be because this group is more likely to be affected by economic adversity, alcoholism, and isolation. It could also be that this group is less inclined to seek help.”

Rosena Allin-Khan, Labour's shadow mental health minister, said, "Suicide is both a public health and social inequality issue, and with the right interventions it is preventable. Today's figures must be a wake-up call for the government."

The ONS also published provisional data for the second quarter of 2020, the peak of the covid-19 pandemic. It showed that there were 6.9 deaths by suicide per 100 ooo people in England. This was the lowest of any quarter since 2001, but the ONS said that the lower number between April and June should be "interpreted with caution," because the pandemic meant that inquests were delayed.

It said, "Given the length of time it takes to hold an inquest (around five months), we do not currently know the total number of suicides that occurred during the coronavirus pandemic." 